\title{
Research Article \\ Self-Transcendence Values, Relationships, and Participatory Practice in Early Childhood Education
}

\author{
Clodie Tal \\ Department of Early Childhood Education, Levinsky College of Education, P.O. Box 48130, Tel Aviv 61481, Israel \\ Correspondence should be addressed to Clodie Tal; clodietal@gmail.com
}

Received 13 March 2014; Revised 11 May 2014; Accepted 14 May 2014; Published 17 July 2014

Academic Editor: Marco Innamorati

Copyright ( 2014 Clodie Tal. This is an open access article distributed under the Creative Commons Attribution License, which permits unrestricted use, distribution, and reproduction in any medium, provided the original work is properly cited.

\begin{abstract}
This study seeks to reveal the circumstances that encourage versus those that block children's participation in the context of daily teacher-children encounters in preschools in Israel. Six cases were selected for analysis-three in which children's participation was enabled and three in which children's participation was blocked by teachers or student-teachers. Participants in the study were five student-teachers doing fieldwork as part of their professional preparation as well as two teachers. Analysis yielded the following conclusions: meaningful participation takes place in the context of a personal, caring relationship with an educator. For challenging situations that require decisions about enabling or denying children's participation, self-transcendence values need to be activated by student-teachers or teachers. Activation of these values is the outcome of personal mental struggle, which is strengthened by having clear, articulated goals to include children in guided and nonguided social encounters. This study suggests that a teacher's espousal of self-transcendence values is among the attributes that have an impact on teachers' representations of relationships, their interactions with children, and the children's participation in daily, preschool social encounters, whose quality may in turn affect the relationships with children. Documentation and critical reflection need to be incorporated into educational practice so that decision-making in challenging situations will be the product of thorough deliberation.
\end{abstract}

\section{Self-Transcendence Values, Relationships, and Participatory Practice in Early Childhood Education}

Although children's participation has been established as policy for educational systems around the world, its implementation is partial, even in Western countries. Using an analysis of six cases of social episodes related to daily teacherchildren encounters in preschools in Israel, this study seeks to improve our understanding of what helps versus what interferes with ensuring the participation of children.

\section{Children's Perspectives and Participation}

Taking children's perspectives into account broadly entails creating conditions that make it possible for children's voices to be heard both in educational institutions and in their communities. As noted in General Comment number 7, para. 5, to the UN Convention on the Rights of the Child (2005):
"The Convention requires that children be respected as persons in their own right. Young children should be recognized as active members of families, communities and societies with their own concerns, interests and points of view."

Recognizing children as active, valuable members of society is not a new societal agenda. In fact, early attempts to ensure children's rights in society and education can be traced back to the early twentieth century. Janusz Korczak, for example, a Polish-Jewish educator and pediatrician, established two orphanages in Poland at the beginning of the twentieth century and directed one of them for some thirty years until his deportation to the Treblinka Extermination Camp with the children and educational staff in 1942. Although Korczak had several times been offered sanctuary on the "Aryan side" by the Council to Aid Jews (Żegota), he repeatedly turned down the offer, saying that he could not abandon "his" children. The outstanding aspect of Korczak's legacy is not only his personal courage and devotion to the children, but his implementation of children's participation on a day-to-day 
basis by instituting a democratic system of communal life in the orphanages he directed [1]. And yet, Silverman claims (p. 283) that one of the shortcomings of Korczak's practice in the orphanages stemmed from its reliance on behavioral mechanisms rather than on a reflective practice that could have led the staff and children to a critical approach of their surroundings.

Although most UN member countries, including Israel, signed and ratified the Convention on the Rights of the Child, recognizing the right of children to voice their interests and concerns, its implementation has been only partial and problematic throughout the world. Thus, we see that in our daily practice, as indicated by Cockburn [2], being knowledgeable of children's perspectives does not necessarily enable the inclusion of children (p. 306).

\section{Relationships and Children's Participation}

Children's participation is perceived ecologically in the context of relationships with and among other children and the cultural context in which they exist [3]. Mannion asserts that "hearing their [the children's] voices. .. is as much about outcomes for adults as much as children" [4, p. 406]. As a result, Mannion suggests that research and practice about children's participation be perceived as being about child-adult relations. The view that inspired the present study is best captured by Woodhead [5, pp. xxi-xxii]:

"Also, children's participation does not diminish
adults' roles and responsibilities. On the contrary,
it increases the challenges to scaffold children's par-
ticipation effectively and appropriately in respect
to their situation and capacities... All of which
highlights the inseparability of promoting chil-
dren's rights and responsibilities from promoting
adults' rights and responsibilities, and the insepa-
rability of participation rights from protection and
provision rights."

Indeed, at the core of pedagogy, we find children's relations with educators. Van Manen claims that a pedagogue is an educator "who feels addressed by children, who understands children in a caring way, and who has a personal commitment and interest in children's education and their growth towards mature adulthood" [6, p. 138]. Furthermore "when these intentions of the educator to give direction are met by responsiveness on the part of the student, then the pedagogical relation has come into existence. In other words, something is expected of the child as well" [6, p. 144].

As part of the attempt to better understand teacherchildren relationships as reciprocal endeavors, Wentzel [7] suggests in a review of theory and research on this topic that relationships should be studied transactionally, in addition to the more common causal or linear model, on the assumption that teacher-child relationships affect children's learning and social participation. Indeed, the pedagogical view of relationships as bidirectional and vertical [8] - in the sense that teachers' roles are to support children emotionally and, at times, to set boundaries on their behavior but never on the expression of their thoughts and feelings [9] - is integrated into the Developmental Systems Model of TeacherChild Relationships [10]. Pianta and colleagues propose that teacher-child relationships are dynamic systems that include the properties of teachers and children; dyadic, bidirectional teacher-child interactions; representations of relationships of teachers and children (beliefs, expectations, and emotions); and external influences (such as the number of children in class, pressures to implement policies and curricula).

Research on teacher-children relationships shows that children's voices are more likely to be heard within the context of adult support and partnership [11]. Furthermore, Fumoto [12] found that key factors enabling good teacher-children relationships were the teachers' "firm understanding of the context of children's development, and their awareness of the role they play in creating this context" (p. 27) as well as the teachers' organizationally enabled autonomy to create social and learning environments in which they are totally involved in supporting young children's growth. Yet it was repeatedly found that teachers tend to be less supportive of children who display challenging behavior [13-15]. Nevertheless, studies also show that there are cases in which teachers are successful at regulating their negative feelings and rejection of disruptive children and subsequently it was found that their sensitivity and patience were associated with the children's more competent social behavior [16-18].

In this study, we suggest that teachers' values be studied as a component of the attributes that might have an impact on their relationships with "regular" and "challenging" children and on the children's participation in daily preschool encounters.

\section{Values and Children's Participation}

The decision to allow children's perspectives to be voiced and to encourage their participation in situations that challenge the teacher is closely related to the teacher's values. After all, state policy recommending children's participation does not automatically translate into an individual teacher's values and actions that express these values.

Values are invisible, inner constructs that supposedly guide our choices. Each teacher or school is bound to be making choices on a daily basis. Democratic values in educationand in early childhood education, in particular-are currently preached, but often not practiced. Values are embedded in daily educational practices (the relationships we form with children, the praise we give, modes of establishing and enforcing rules, how we deal with disruptions and opposition from children, what texts we choose, what kind of student work we post in our classrooms, and so on).

"A value is an enduring belief that a specific mode of conduct or end-state of existence is personally or socially preferable to an opposite or converse mode of conduct or endstate of existence" [19, p. 5]. Williams [20] claims that overt and articulate values turn into criteria that guide one's judgments and preferences, whereas latent and unconscious values impact daily choices. This approach suggests that values cannot be fully understood or measured without reference to 
attitudes and behaviors that are the essence of making and expressing choices.

Schwartz's theory of value structure and content is by far the most elaborate and empirically validated. Schwartz claims that "The crucial content aspect that distinguishes among values is the type of motivational goal they express" [21, p. 438]. He defined and empirically validated ten motivationally distinct types of values expressing comprehensive, universal requirements of human existence to which all individuals and societies must be responsive: needs of individuals as biological organisms, requisites of coordinated social interaction, and survival and welfare needs of groups [21, 22]. Therefore, each type is defined in terms of the motivational goals expressed as well as the single values they represent. Furthermore, Schwartz suggested that values are organized along two bipolar dimensions. One contrasts "openness to change" and "conservation" values; this dimension captures the conflict between values that emphasize independence of thought, action, and feelings plus readiness for change (selfdirection, stimulation) and values that emphasize order, selfrestriction, preservation of the past, and resistance to change (security, conformity, and tradition). The second dimension contrasts "self-enhancement" and "self-transcendence" values. This dimension captures the conflict between values that emphasize concern for the welfare and interests of others (universalism, benevolence) and values that emphasize pursuit of one's own interests and relative success and dominance over others (power, achievement) [23, p. 8].

\section{Summary and the Research Question}

To sum up, relationships of young children with adults (parents, caregivers, and teachers) are bidirectional and, ideally, vertical and asymmetrical, meaning that adults, although affected by the children, are supposed to respond to the young's emotional needs, but that children are not supposed to take responsibility for the adults' welfare. These relationships are reflected in daily encounters-interactions in which children are active participants or excluded by teachers, peers, or themselves. Thus, the challenge for parents and teachers alike is to be responsive to children's needs in situations that take a toll on them, that is, in situations in which the adult's needs are likely to be jeopardized in the process of fulfilling the child's needs. This kind of decisional crossroads is related to the activation of values by adults. Therefore, the aim of this study is to reveal the circumstances that enable educators in preschools to allow for children's participation in daily events that form part of their life-world. The study is based on the analysis of cases-in some of which children's participation was enabled and in others, where the children's participation was denied by teachers or student-teachers or the children themselves. The interpretation and analysis of the cases included in this study were guided by the question: What are the contexts related to adult-child relationships and adult values that are reflected in their decisions to promote or impede young children's participation?

The Developmental Systems Model of Teacher-Child Relationships [10] recognizes that teacher-child relationships include properties of teachers and their representations of relationships. We suggest that teachers' self-transcendence values are one such property that affects both their representations of relationships and their daily interactions with "regular" and "challenging" children. To the best of our knowledge, teacher's self-transcendence values have not yet been studied as a property of the teacher-child relationships system.

\section{Methodology}

This study is based on an analysis of six cases describing teacher-children encounters in daily preschool situations that were chosen from a pool of cases: three in which children were encouraged to participate and three in which children were denied participation by their teacher or student-teacher or, in one case, the child initially excluded himself from the activity. These cases were analyzed to enable a better understanding of circumstances that encourage versus those that hinder children's participation. All cases took place in either "regular" or special education preschools in the center of Israel.

Five of the six cases were selected from a pool of social episodes focused on meaningful teacher-young children encounters that were extracted from students' assignments in courses taught by the author. The criteria for inclusion of a social episode in this study included (1) a clear occurrence of participation or exclusion, ensuring an equal number of participation/exclusion episodes and (2) the students' accounts of the episode included reports of their thoughts and feelings concerning the story. The sixth episode (Case 1, below) was based on the author's observation as it showed a situation similar to Case 2, but with a less fortunate outcome in terms of participation for the child involved.

Students in the courses taught by the author are routinely asked for permission to use their accounts in future lectures and articles. Furthermore, students are encouraged to use their peers' written social episodes for their own research studies, subject to their colleagues' consent. Students' rare requests to not post or use their accounts are strictly honored by the author and thus have not been included in the pool of cases mentioned above. The identity of participants has not been disclosed and the first names used are not the participants' real names.

This study has been guided by a constructivist, groundedtheory approach. Conceptualization of proposed relations between values, relationships, and participatory practice is compatible with Strauss and Corbin's evolved grounded theory approach, namely, "Theorizing is the act of constructing from data an explanatory scheme that systematically integrates various concepts though statements of relationship" [24, p. 25]. The cases examined consist of one or more social episodes and occasional reflections on these episodes by the student-teachers. Episode analysis was used for this study as episodes are considered the most basic unit of social interaction. Most episodes are about something specific. The study of the social world through analysis of social episodes was first proposed by Harré and Secord [25]. 
Participants are those who participated in the episodes in the six cases of this study. Five of the episodes were written and reported by five student-teachers and one by the author of this paper.

The six cases, in brief, are as follows.

Case 1. "An end-of-the-year party should be a surprise for the parents." This is an account by the author based on extensive preschool observations and discussions with the teacher and the parents of a boy who ultimately did not participate in a party. The child has some language difficulties, primarily in expressive language, and is often hard to understand. Toward the end of the school year, a party was planned. The boy's mother asked the teacher for the songs that would be sung at the party as she could not understand the child's reply and she wanted to rehearse the songs with him at home. The teacher refused, stating that the events of the party were to be a surprise for the parents, which eventually led to the child's failure to participate in the party (July 2013).

Case 2. "Those planning not to attend the party are not allowed to participate in rehearsals." This is an account by a second-year student-teacher participating in a social competence course and is based on several observations and a specific episode in which the student participated. The child, identified as a troublemaker, was excluded from rehearsals on the grounds that he would not be attending the party due to a preplanned family vacation, with the exception of one rehearsal when the student volunteered to dance with the boy (June 2013).

Case 3. "Having goals helps overcome motivation crises." This account was provided by a second-year student-teacher also participating in a social competence course. She wrote about her internal struggle to persevere with a child who had a strong tendency to abstain from social activities-the temptation to choose actions that would probably be more fun for her. She ultimately decided to persevere, and as a result, the boy participated in free play activities and social time (June 2013).

Case 4. "[I decided to] stop acting like an automaton." This account was written by a third-year student-teacher in a classroom management seminar following her guided observation of a videotaped activity - trying to understand why several children in each group did not participate in the activity. Following the observations and reflection, she transformed how she led the discourse with the children: she sat closer to them and allowed them to initiate, rather than leading the discussion herself. Ultimately, she managed to engage all the children in the discourse (May 2013).

Case 5. "A missed opportunity to learn." This account was written by a second-year student-teacher in a professional development program for teaching in both regular and special education classes. The student was involved in a classroom management course and the account was part of a class assignment. The account includes two episodes from a special education class. In the first, the student notices a boy throwing sand on his peers during free, outdoor play; the boy refuses to comply with her request to talk to her about his misbehavior. As a result she decides to punish the child by excluding him from free play for the whole day. The teacher and her assistant back the student up and the three repeatedly explain to the boy that he is being punished for noncompliance with the student, not for his attempt to hurt other children. Although initially she felt uncomfortable about excluding the boy from the playground, support from the teacher and assistant eliminated student's discomfort with her decision. A few weeks later, another child took more treats than allowed by the same student-teacher. Although the child himself said that his misdeed consisted of not leaving enough treats for the other children, the student insisted that the boy be punished for not complying with the student's directives, rather than for his inconsiderate behavior toward his peers (June 2008).

Case 6. "Overcoming the temptation to exclude." This case includes a series of accounts by a second-year student-teacher in a social competence course related to her continuous efforts to cope with a highly disruptive boy in her study group. Although warned by both her field supervisor and mentor about this boy's misbehavior, and advised not to include him in her group, the student, following her reflections, decided not to exclude him from the group, but to develop strategies such as overlooking disturbances and reinforcing engagement in learning and group discussion (June 2005).

\section{Findings}

An analysis of the six cases revealed the following themes, reflecting circumstances that either facilitated or interfered with the children's participation. Following presentation of these themes, we offer in the discussion below our conceptualization of how these circumstances impact relationships in the dynamic of teachers' values, teacher-children relations, and fostering children's participation.

(1) Action without Reflection: The Banality of Excluding Children from Activities. Teachers who are not enrolled in some type of professional development track-and thus required by someone to document their practice-often act without pondering or reflecting upon their choices. Cases 1 and 2 above show common practices related to preparing preschool parties as part of the educational routine. Neither of the teachers paused at any time to consider the implications of her decisions on the children's wellbeing. The participation of the children was denied on practical grounds: that the party was supposed to be a surprise to the parents or that participating in rehearsals is futile if the child will not be attending the party. In their decisions, teachers seemed to attribute more importance to the success of the party than to the child's wellbeing. This is a value issue since immediate personal comfort or the desire to please parents by surprising them was preferred over the child's wellbeing without a second thought. Thus, in everyday practice, at least as revealed in these two cases, the decision to exclude a child from important activities seems to be made too easily. We conclude that practicing pedagogy without documenting episodes or 
creating opportunities to reflect upon decisions tends to interfere with a pedagogy that fosters the participation of children. The teachers' precise considerations cannot be evaluated as they were not offered, and analysis in this case is made only on the basis of the outcome of their decisions.

(2) Clearly Articulated Goals Can Guide Decisions That Favor Inclusion, Particularly When Coping with Challenging Behavior. Good examples of this can be found in Cases 3, 4, and 6. Here is what the student Gila (Case 3) wrote with reference to her perseverance in encouraging a child to take part in social activities:

"I learned about myself that it was not always easy for me to cope, in spite of being aware of my goals and having support and guidance from the college and field mentors...I learned that when having a hard time, I still stick to my goals (Gila, June 2013)."

Michla's account (Case 6) also shows how value-oriented goals helped her refrain from excluding a child:

"Throughout implementation of the intervention
plan, I often found myself stopping and thinking
about what I ought to do now - as naturally the
will [arose] to exclude him, to send him away
from the group, as he frequently interfered with
the progress of the lesson...During a guided, group-
learning session, Maor started to play with parts of
boxes that had been placed on the table. He spread
chocolate powder on another child's head. My first
thought was to expel Maor from the group, to send
him back to his class; nevertheless I told him that
he had been very attentive [before the incident]
and I asked him to keep going with the group
a little longer and then we will all prepare the
chocolate drink... (Michla, May 2005; emphasis
added)."

Gila's and Michla's reflective approach impels them to check and double-check themselves and to openly admit to having a hard time sometimes with sticking to the decision to include a child. Having clear goals in mind related to the child's inclusion in groups or social activities is helpful in reinforcing their perseverance. Interestingly, in Gila's account we witness a case in which the boy himself constantly refrained from participating in social activities. It was the student-teacher's initiative to implement a plan that aspired to include him in the social network of the preschool. Were she-like the teacher-to allow things to flow in keeping with the boy's expressed will, he would have remained socially isolated. In the two cases presented, inclusion of a child was facilitated by the student-teachers' adherence to their goalsgoals that reflect their values. In both cases, the students, though feeling a transient temptation to prefer personal comfort (self-enhancement values), seem to have chosen to transcend their own, immediate wellbeing for the sake of contributing to the child's emotional and social welfare.

In the excerpt that follows, we are privileged to witness Selma's contemplation about her initial tendency to overlook some children's failure to participate in a group and learn about her open acknowledgement of her preference-albeit transient-for self-enhancement values:

"Throughout the learning session, I didn't pay at-
tention at all to Peter's and Nira's almost complete
lack of participation and, as a matter of fact, I did
not notice their lack of participation during the
session. I simply indulged "flowing" at the pace of
the dominant children. Three dominant children
dictated the pace. And I enjoyed their reactions,
which contributed to advancing the session, with-
out taking into account the other children or
paying any attention to them (Selma, May 2013;
emphasis added)."

We therefore conclude that having well-articulated, personal goals that reflect the importance attributed to inclusion by the educator is helpful in attaining children's participation. Furthermore, we witness conscious, internal conflicts in all these cases before a decision is made to prefer the child's welfare and thus to express self-transcendence values in actual actions affecting children.

(3) Self-Transcendence Choices Are Never Made Automatically; They Are the Result of Mental Struggle and Critical Reflection. What emerged from the analysis of the cases and is reflected in the excerpts above is that a decision to prioritize the child's needs over personal gratification is always the result of an internal mental struggle. It is important to acknowledge that human nature seems to favor personal comfort and benefit, whereas assuring the welfare of a challenging child requires effortful self-regulation. Michla (Case 6) and Selma (Case 3) beautifully express these ideas in their accounts:

\section{"Throughout implementation of the intervention plan, I often found myself stopping and thinking about what I ought to do now-as naturally the will [arose] to exclude him, to send him away from the group as he frequently interfered with the progress of the lesson (Michla, May 2005)."}

"In retrospect, it seems to me that I behaved in an automatic manner, without paying attention to what was happening in the session...I simply indulged "flowing" at the pace of the dominant children (Selma, May 2013)."

It appears that even in cases such as these in which educators do have clear goals of including children in activities and encouraging their participation-even when they have a clear orientation to favor the child's welfare-when confronted with hardships that challenge their own tranquility, the final decision to include, or not to exclude, children is the result of deep thought and mental struggle.

(4) Decisions Related to Childrens Inclusion/Participation Are Always Taken in the Context of Relationships with and among the Children. Since pedagogy is always about relationships, 
mindful decisions about allowing or denying the participation of children are always "personal" and related to the quality of the relationships with and among the children. It is interesting to notice that in the first two cases, teachers' decisions to disallow (Case 2) or not exert any effort to enable (Case 1) children's participation seemed-from a bystander's perspective-impersonal, distanced; they in no way took into consideration relationships and feelings. It is fair to note that we do not know from these two accounts about the real relationships and interactions with these children nor how they were represented in the teachers' minds. In contrast with these two cases, we present below excerpts from two student-teacher accounts, which acknowledged the impact that relationships had on their state of mind and decisions:

\section{"My relationship with the child changed during implementation of the intervention plan. As I worked with him, Inoticed that Maor is not as bad as everyone else thinks of him...The best outcome of the intervention plan was the change in my relationship with the child. At the beginning I almost agreed with the teacher and was about to give up on Maor. Today things have changed (Michla, June 2005)."}

Michla's account shows that she attributes the success of her intervention plan (to enable the boy's full participation in learning and social groups) to her improved relationship with him. She seemed to work hard to stop seeing the "bad boy" in Maor and to disregard other people's warnings leading to the futility of her efforts to fight for his right to participate. Michla's account shows that forming and improving relations with children is guided by mental work and critical reflection. The reflection might include relationships between adults and the child as presented by Michla or relationships with other children as evident in Gila's account:

\section{"I so much wanted to spend time with the other children and pay attention to Lyam [the girl I worked with in the first semester], but I knew this would mean giving up on myself and the boy, and I eventually continued to encourage Ohr to participate... when he knows in advance [the topic to be studied] before all the other children, so he can feel secure (Gila, June 2013).”}

Gila's account helps shed light on the usefulness of being open with oneself and admitting a preference to be closer to some children than to others-an admission that takes some courage. Her account also casts light on the need to acknowledge comparisons we make in our relationships with children, and to activate "professional" attitudes that counteract our basic drive to behave in ways that make us feel good at the expense of another child's wellbeing. Ultimately, Gila decided to take action on behalf of Ohr, and Michla decided to stick to her determination to include Maor in her group, regardless of the personal price they would have to pay. From their accounts, it seems they consciously pondered both the children's and their own needs and that a sense of caring and personal and professional responsibility are what helped them prefer fulfillment of the child's needs. Activating one's self-transcendence values seems to mean that one needs to allow oneself to feel and think and to take these feelings and thoughts into consideration, though ultimately choosing to act in accord with professional-moral principles.

\section{Discussion}

Fostering inclusion and the participation of "challenging" children emerge in this study as the outcome of a thoughtful series of acts and decisions that result from mental struggle and critical reflection that are focused, inter alia, on our human weakness to prefer our own comfort, welfare, or personal promotion. "Natural" preference needs to be acknowledged and resisted on a daily basis. Decisions that favor children's participation must be embedded in close relationships between educators and children. Furthermore, ample opportunities are needed for documenting and reflecting upon social episodes, as difficulties and challenges are to be expected-they are part of the reality of preschools (and schools in general). The unfortunate outcome of dismissing from our mind and conscience any troubling, guilt-related ideas is clearly reflected in the fifth case, in which the studentteacher, her field mentor, and assistant hastily decide to punish two boys for disobeying the student rather than engaging in a thorough analysis of the case and coming up with solutions that might contribute to the emotional welfare and moral development of the children involved. One of the main stumbling blocks to the participation of children appears to be our default tendency to favor immediate comfort and self-promotion (self-enhancement). This challenge seems to constitute the real difficulty of self-transcending our personal needs for the sake of the children we educate [22, 23]. Although, as stated by Schwartz, people tend to differ in terms of their relative endorsement of self-transcendence versus self-enhancement values, what appears in this study is that endorsing self-transcendent values is a dynamic process as opposed to a fixed personal attribute. In daily activities, for example, someone having a self-transcendence orientation may choose actions that reflect self-enhancement at a certain point in time, depending on particular circumstances. Michla (Case 6) did at one point decide to follow her mentor's advice and expel Maor from her group. However, the power of the self-transcendence value orientation, reflected in clearly articulated pedagogical goals that favor children's participation, ultimately prevailed.

Acknowledging the importance of caring, intimate relationships with children (closeness as defined by Pianta [26]) -relationships that are vertical in nature [8] - seems to serve as the context for the development of self-transcendence value preferences among educators; these require ratification on a daily basis as decisions are made about children's challenging behavior. Furthermore, in light of the findings of this study, we suggest that the Developmental System of TeacherChildren Relationships [10] integrate self-transcendence/selfenhancement values as a component of the teacher's personal attributes. Self-transcendence/self-enhancement values seem 
to be related to both the teachers' representations of relationships as asymmetrical versus symmetrical, for example, and to their daily interactions with children. Subsequently, daily interactions with children, particularly in challenging situations in which teachers or student-teachers regulate their negative feelings and give up the exclusion option of a child from an encounter-as beautifully presented in Cases 3 and 6-are likely to strengthen relationships with the children and the likelihood of opting for self-transcendence values in the future.

Authentic and meaningful child participation requires a radical shift in adult thinking and behavior from an exclusionary to an inclusionary approach to children and their capabilities [27]. This study reveals some of the processes necessary to perform this shift.

Therefore we focused in this study primarily on factors related to daily teacher-children encounters that have an impact on children's participation. We emphasized the educators' responsibilities. We did not examine here factors in the macrosystem that may affect lives and decisions related to children's participation in everyday situations, although we know that national and local education systems often make it difficult for teachers to be thoroughly attentive to the children; these factors are not addressed in this study. National policies may expect teachers to encourage children's participation while, at the same time, demanding that learning be speeded up to please parents and complete more tasks. The education system in Israel, to put it mildly, does not do a good job in supporting its educators. And yet some of the student-teachers participating in this study showed caring, a willingness to place the children's needs ahead of their own, and an ability to learn and change the planned course of action in order to enable children's participation.

Practical recommendations drawn from the present study can be summarized as follows.

(1) Professional development at all stages-even after graduation-must make extended use of documentation and personal or joint analysis of social episodes, particularly in challenging situations.

(2) Mentors, teachers, and student-teachers need to acknowledge that encouraging children's participation means, quite often, giving up power, giving up comfort, and being prepared to experience mental and emotional distress that accompanies the decision-making process in challenging situations.

(3) The articulation of clear pedagogical goals throughout one's professional development that favor children's participation-and experiencing the turmoil and the satisfaction that may ensue-can serve as antidotes to ambivalent policy and occasional lack of support from superintendents, principals, and politicians.

As for future studies, to better understand factors involved in the Developmental System of Teacher-Children Relationships, we suggest that more cases be examined that focus on daily encounters with young children who are either included or excluded from activities, and that these inquiries be supplemented by the young children's perspectives of their relationships with their teachers and their feelings and thoughts concerning the quality of participation in preschool social encounters. Furthermore, the author will attempt to perform a larger-scale study in which student-teachers' own accounts of social episodes about children's participation and inclusion are related to their responses on Schwartz's Portrait Value Questionnaire (PVQ) [23].

\section{Conflict of Interests}

The author hereby declares that there is no conflict of interests regarding the publication of this paper.

\section{References}

[1] M. Silverman, The Child Is a Person: Janusz Korczak's Educational Thought, Mofet Institute, Tel Aviv, Israel, 2012 (Hebrew).

[2] T. Cockburn, "Children and deliberative democracy in England," in A Handbook of Children and Young People's Participation: Perspectives from Theory and Practice, B. Percy-Smith and N. Thomas, Eds., pp. 306-318, Routledge, New York, NY, USA, 2010.

[3] U. Bronfenbrenner, The Ecology of Human Development, Harvard University Press, Cambridge, Mass, USA, 1979.

[4] G. Mannion, "Going spatial, going relational: why "listening to children" and children's participation needs reframing," Discourse: Studies in the Cultural Politics of Education, vol. 28, no. 3, pp. 405-420, 2007.

[5] M. Woodhead, "Foreword," in A Handbook of Children and Young People's Participation: Perspectives from Theory and Practice, B. Percy-Smith and N. Thomas, Eds., pp. 19-22, Routledge, New York, NY, USA, 2010.

[6] M. van Manen, "Pedagogy, virtue and the narrative identity in teaching," Curriculum Inquiry, Summer, vol. 4, no. 2, pp. 135170, 1994.

[7] K. R. Wentzel, "Teacher-student relationships and adolescent competence at schools," in Interpersonal Relationships in Education: An Overview of Contemporary Research, T. Wubbels, P. den Brok, J. van Tartwijk, and J. Levy, Eds., pp. 19-37, Sense Publishers, Rotterdam, The Netherlands, 2012.

[8] R. Hinde, Relationships: A Dialectical Perspective, Psychological Press, Hove, UK, 1997.

[9] B. K. Barber, H. E. Stolz, J. A. Olsen, W. A. Collins, and M. Burchinal, "Parental support, psychological control, and behavioral control: assessing relevance across time, culture, and method," Monographs of the Society for Research in Child Development, vol. 70, no. 4, pp. 1-147, 2005.

[10] R. C. Pianta, B. Hamre, and M. Stuhlman, "Relationships between teachers and children," in Comprehensive Handbook of Psychology: Educational Psychology, W. Reynolds and G. Miller, Eds., vol. 7, pp. 199-234, John Wiley \& Sons, Hoboken, NJ, USA, 2003.

[11] E. K. M. Tisdall and J. Davis, "Making a difference? Bringing children's and young people's views, into policy-making," Children and Society, vol. 18, no. 2, pp. 131-142, 2004.

[12] H. Fumoto, "Teacher-child relationships and early childhood practice," Early Years, vol. 31, no. 1, pp. 19-30, 2011. 
[13] H. E. Brophy-Herb, R. E. Lee, M. A. Nievar, and G. Stollak, "Preschoolers' social competence: relations to family characteristics, teacher behaviors and classroom climate," Journal of Applied Developmental Psychology, vol. 28, no. 2, pp. 134-148, 2007.

[14] F. A. Sava, "Causes and effects of teacher conflict-inducing attitudes towards pupils: a path analysis model," Teaching and Teacher Education, vol. 18, no. 8, pp. 1007-1021, 2002.

[15] J. L. Spilt and H. M. Y. Koomen, "Widening the view on teacherchild relationships: teachers' narratives concerning disruptive versus nondisruptive children," School Psychology Review, vol. 38, no. 1, pp. 86-101, 2009.

[16] B. K. Hamre and R. C. Pianta, "Can instructional and emotional support in the first-grade classroom make a difference for children at risk of school failure?" Child Development, vol. 76, no. 5, pp. 949-967, 2005.

[17] P. Riley, H. M. G. Watt, P. W. Richardson, and N. de Alwis, "Relations among beginning teachers'self-reported aggression, unconscious motives, personality, role stress, self-efficacy, and burnout," in Interpersonal Relationships in Education: An Overview of Contemporary Research, T. Wubbels, P. den Brok, J. van Tartwijk, and J. Levy, Eds., pp. 151-166, Sense Publishers, Rotterdam, The Netherlands, 2012.

[18] S. E. Rimm-Kaufman, D. M. Early, M. J. Cox et al., "Early behavioral attributes and teachers' sensitivity as predictors of competent behavior in the kindergarten classroom," Journal of Applied Developmental Psychology, vol. 23, no. 4, pp. 451-470, 2002.

[19] M. Rokeach, The Nature of Human Values, The Free Press, New York, NY, USA, 1973.

[20] M. Williams Jr., "Change and stability in values and value systems: a sociological perspective," in The Nature of Human Values, M. Rokeach, Ed., Free Press, New York, NY, USA, 1979.

[21] S. H. Schwartz and L. Sagiv, "Identifying culture-specifics in the content and structure of values," Journal of Cross-Cultural Psychology, vol. 26, no. 1, pp. 92-116, 1995.

[22] S. H. Schwartz, "Universals in the content and structure of values: theory and empirical tests in 20 countries," in Advances in Experimental Social Psychology, M. Zanna, Ed., vol. 25, pp. 1-65, Academic Press, New York, NY, USA, 1992.

[23] S. H. Schwartz, "An overview of the schwartz theory of basic values," Online Readings in Psychology and Culture, vol. 2, no. 1, 2012.

[24] A. Strauss and J. Corbin, Basics of Qualitative Research: Techniques and Procedures of Developing Ground Theory, Sage, Thousand Oaks, Calif, USA, 2nd edition, 1998.

[25] R. Harré and P. F. Secord, The Explanation of Social Behavior, Basil Blackwell, Oxford, UK, 1972.

[26] R. C. Pianta, Enhancing Relationships between Children and Teachers, American Psychological Association, Washington, DC, USA, 1999.

[27] UNICEF, The State of the World's Children 2003, UNICEF, New York, NY, USA, 2002. 

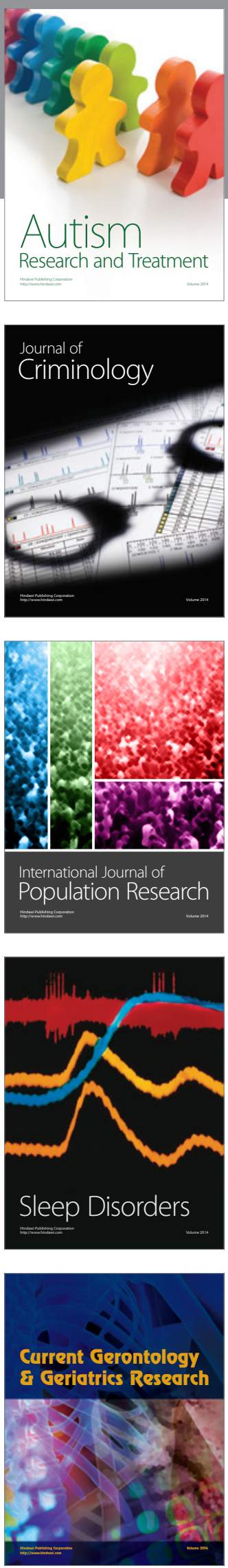
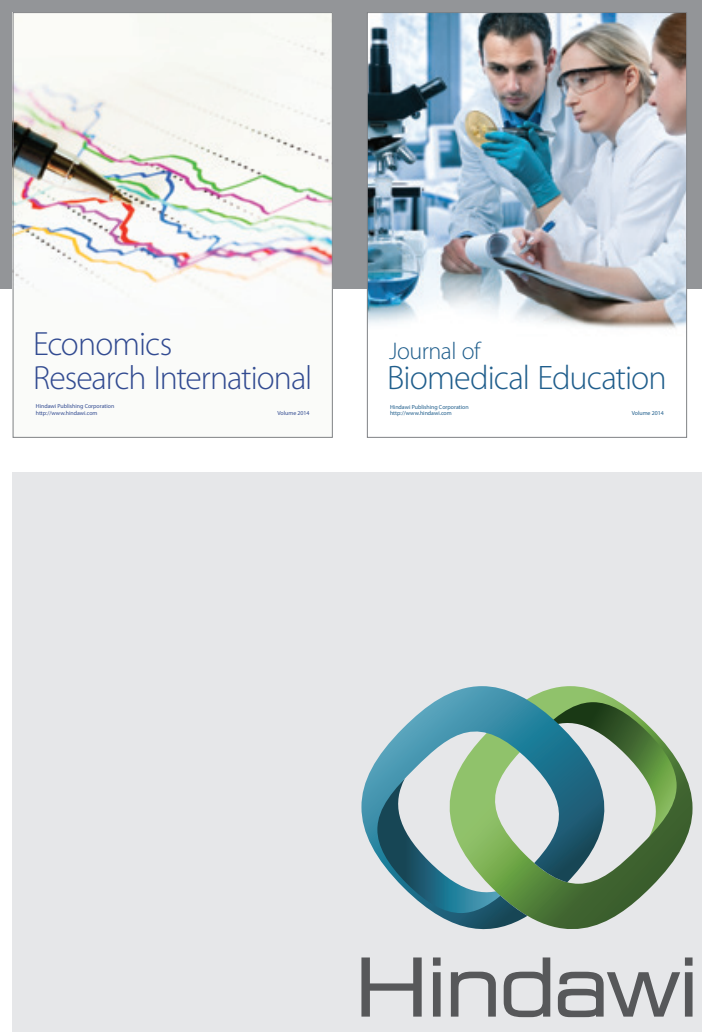

Submit your manuscripts at

http://www.hindawi.com
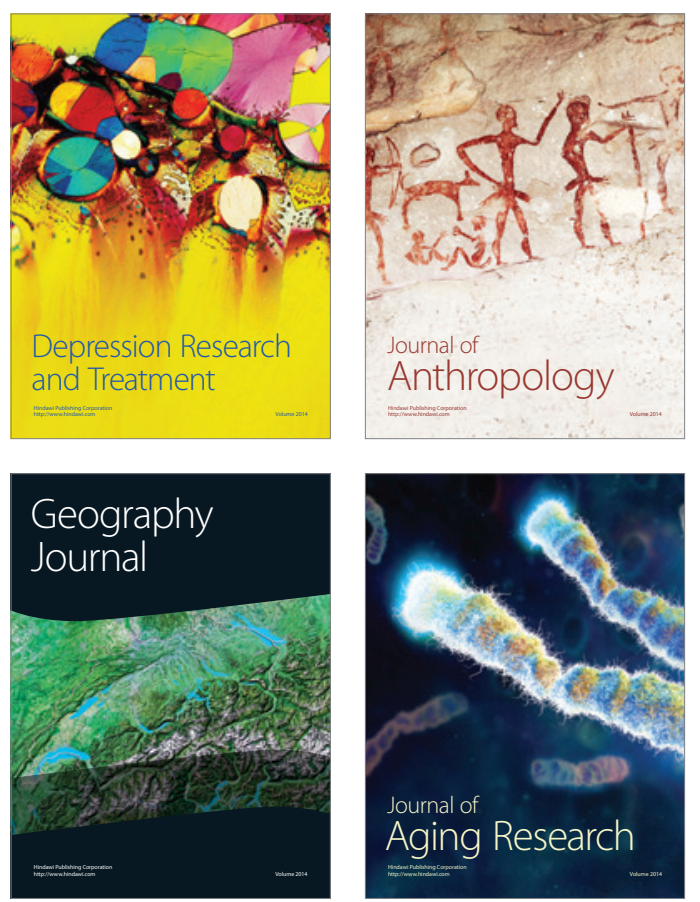
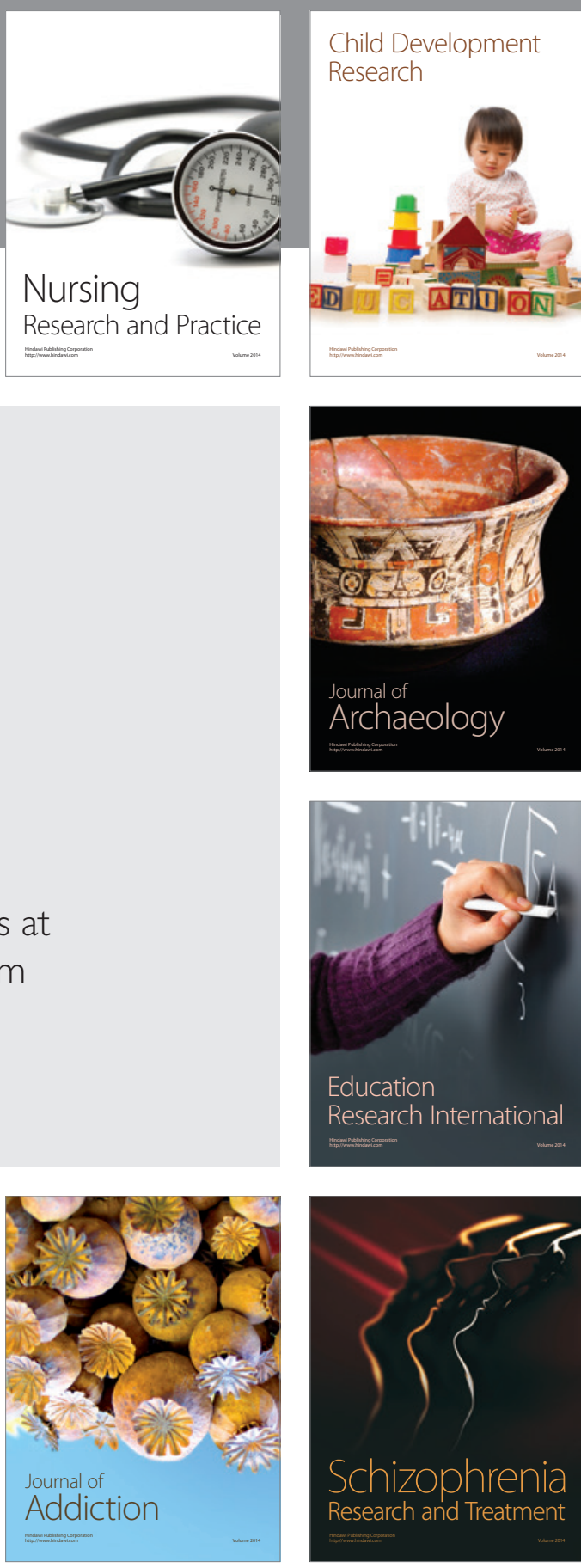

(D)
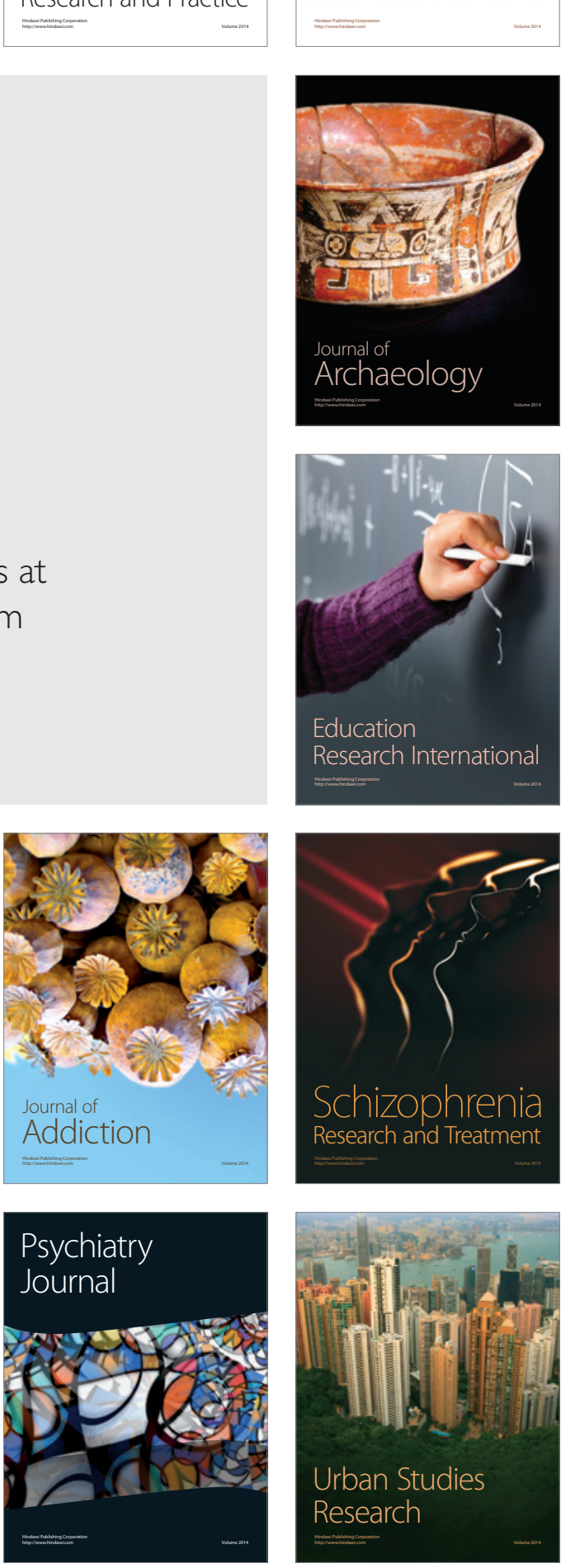